\title{
BMJ Open Alcohol consumption over time and mortality in the Swedish Women's Lifestyle and Health cohort
}

\author{
Idlir Licaj, ${ }^{1}$ Sven Sandin, ${ }^{2}$ Guri Skeie, ${ }^{1}$ Hans-Olov Adami, ${ }^{2,3}$ Nina Roswall, ${ }^{4}$ \\ Elisabete Weiderpass ${ }^{1,2,5,6}$
}

To cite: Licaj I, Sandin S, Skeie G, et al. Alcohol consumption over time and mortality in the Swedish Women's Lifestyle and Health cohort. BMJ Open 2016;6: e012862. doi:10.1136/ bmjopen-2016-012862

- Prepublication history and additional material is available. To view please visit the journal (http://dx.doi.org/ 10.1136/bmjopen-2016012862).

Received 27 May 2016 Revised 13 October 2016 Accepted 18 October 2016

CrossMark

For numbered affiliations see end of article.

Correspondence to

Dr Idlir Licaj;

idlir.licaj@uit.no

\section{ABSTRACT}

Background: Alcohol consumption is steadily increasing in high-income countries but the harm and possible net benefits of light-to-moderate drinking remain controversial. We prospectively investigated the association between time-varying alcohol consumption and overall and cause-specific mortality among middleaged women.

Methods: Among 48249 women at baseline (33 404 at follow-up) in the prospective Swedish Women's Lifestyle and Health cohort, age 30-49 years at baseline, we used repeated information on alcohol consumption and combined this method with multiple imputation in order to maximise the number of participants and deaths included in the analyses. Multivariable Cox regression models were used to calculate HRs for overall and cause-specific mortality.

Results: During $>900000$ person/years, a total of 2100 deaths were recorded through Swedish registries. The median alcohol consumption increased from $2.3 \mathrm{~g} /$ day in 1991/1992 (baseline) to $4.7 \mathrm{~g} /$ day in 2004 (follow-up). Compared with light drinkers (0.1-1.5 g/day), a null association was observed for all categories of alcohol consumption with the exception of never drinkers. The HR comparing never with light drinkers was 1.46 (95\% Cl 1.22 to 1.74). There was a statistically significant negative trend between increasing alcohol consumption and cardiovascular and ischaemic heart diseases mortality. The results were similar when women with prevalent conditions were excluded.

Conclusions: In conclusion, in a cohort of young women, light alcohol consumption was protective for cardiovascular and ischaemic heart disease mortality but not for cancer and overall mortality.

\section{INTRODUCTION}

According to the WHO, alcohol consumption is steadily increasing in high-income countries and causally related to upper aerodigestive tract (UADT), liver, colorectal and female breast cancer. ${ }^{1}$ Worldwide, in 2012, $4 \%$ of all global female deaths were attributable to alcohol consumption. Alcohol-attributable deaths are highest in the European Region

\section{Strengths and limitations of this study}

- This study was based on information on dietary and lifestyle exposure collected in the Swedish Women's Lifestyle and Health prospective cohort study of young and middle-aged women.

- We used repeated information on alcohol consumption and combined this method with multiple imputation in order to maximise the number of participants and deaths included in the analyses.

- Analyses excluding participants with morbid condition at cohort entry, and isolating women who stopped drinking between baseline and follow-up minimised reverse causality bias in our study.

- Main limitations included the small number of cases for specific causes of death among women drinking $\geq 15 \mathrm{~g} /$ day and that we had no information on excessive alcohol consumption in the Swedish Women's Lifestyle and Health cohort study.

- Although statistical models included many potentially relevant adjustment factors, residual confounding might partially account for the observed associations.

and particularly in high-income countries within Europe. ${ }^{2}$ In two recent studies, heavy alcohol consumption increased mortality from alcohol-related cancer (ARC), external causes and 'other causes' (external causes of deaths), ${ }^{3}{ }^{4}$ while no association was observed for coronary heart disease (CHD) and other cardiovascular diseases (CVDs). ${ }^{3}$ A J-shaped association between alcohol and all-cause mortality was been observed in two recent meta-analyses of prospective studies. ${ }^{5} \quad 6$ Moderate alcohol drinking has been associated with a reduction in cardiovascular mortality $^{7}$ but this is not consistent among studies. A recent meta-analysis found that low-volume alcohol consumption has no net mortality benefit compared with lifetime abstention or occasional drinking. ${ }^{8}$ Some investigators argue that this proposed benefit depends on the 
choice of reference group. ${ }^{9}$ Studies on light-to-moderate alcohol consumption over time and risk of death in women are, however, scarce. ${ }^{10}$ Within the Swedish Women's Lifestyle and Health (WLH) Study, an earlier analysis showed that a possible beneficial effect of light-to-moderate alcohol drinking was limited to CVD/ CHD mortality, with no measurable increase in overall cancer mortality. ${ }^{11}$ In the current study, we quantify the associations between time-varying alcohol consumption and overall and cause-specific mortality, including cancer mortality-separating ARC and other cancers-death from CVDs, violence and injuries and other causes.

\section{METHODS}

\section{Study population}

The WLH cohort is a prospective study of women recruited between August 1991 and June 1992 in the Uppsala Healthcare Region, Sweden when 96000 female residents aged 30-49 years were randomly selected and mailed a self-report questionnaire. Of these, 49259 (51\%) women gave their informed consent and were enrolled in the WLH study. A follow-up questionnaire, mailed between February 2003 and January 2004 to all cohort participants who were still alive, was completed and returned by 34402 women. Both the baseline (1991/1992 questionnaire) and the follow-up questionnaire requested information regarding anthropometric measurements, personal history of diseases, smoking and drinking habits, diet and physical activity. The cohort profile has been previously described in detail. ${ }^{12}$ We excluded participants with implausible energy intake, outside the 1st and 99th centiles, and those who emigrated without re-immigration before enrolment $(n=990)$. The final cohort comprised 48249 women.

\section{Measure of alcohol consumption}

In the baseline questionnaire, each woman was asked: 'How much alcohol do you drink per week, month or year?' for five different types of alcohol: class II beer ( 1 glass $=2 \mathrm{dL})$, class III beer $(1$ glass $=2 \mathrm{dL})$, wine ( 1 glass $=1 \mathrm{dL})$, fortified wine $(1$ glass $=4 \mathrm{cL})$ and spirits (1 glass $=4 \mathrm{cL}$ ). Response categories were open, and included number of glasses per week, month and year, respectively. Furthermore, it was possible to answer that alcoholic beverages were consumed seldom or not at all. In the follow-up questionnaire, each woman was asked if she drank alcohol, and if the answer was affirmative, she was asked 'How often on average do you usually drink the following kinds of alcohol?' for seven different types of alcohol: low alcohol beer, beer, white wine, red wine, dessert wine and spirits. Apart from these questions, corresponding to the questions in the baseline questionnaire, each woman was asked about binge drinking and if alcohol was usually consumed with meals. These questions were not included in this study. The follow-up questionnaire contained similar corresponding questions regarding alcohol intake. The reported glasses of alcohol were converted to grams of alcohol using food composition data from the Swedish National Food Administration (http://www7.slv.se/SokNaringsinnehall/ Home/ToggleLanguage) for both the baseline and follow-up questionnaires. This gives the grams of alcohol per glass for the aforementioned different categories of alcoholic beverages, and thus allows conversion of number of glasses to grams of alcohol.

\section{Follow-up and mortality}

Cohort members were followed from August 1991 through 31 December 2012 by linking the cohort to the national registers (Death Register, Cancer Register and Emigration Register) through their individually unique national registration number, ${ }^{12} 13$ making follow-up virtually complete. ${ }^{14}$

All Swedish death certificates are issued by a physician and the quality of these have been found to be high. ${ }^{15}$ Causes of death were classified according to the International Classification of Diseases, 10th Revision, codes (ICD-10 codes or corresponding). In this study, the following seven causes of death were considered: ARC as defined by the International Agency for Cancer Research, ${ }^{16}$ (breast cancer C50; colorectal cancer C18C20; UADT (including cancer of the mouth, C01-C15, larynx, C32, and excluding salivary gland, C08)), other cancers (all cancer mortality excluding ARC mortality), CVD mortality excluding ischaemic heart diseases mortality $\mathrm{N}=177$ including (chronic rheumatic heart diseases I05-I09; hypertensive diseases I10-I15; pulmonary heart disease and diseases of pulmonary circulation I26-I28; other forms of heart disease I30-I52; cerebrovascular diseases I60-I69; diseases of arteries, arterioles and capillaries I70-I79; diseases of veins, lymphatic vessels and lymph nodes, not elsewhere classified I80-I89; other and unspecified disorders of the circulatory I95-I99), ischaemic heart diseases (IHD) I20-I25 which were studied separately, external causes of deaths directly or indirectly related to alcohol consumption including traffic injuries, poisoning, drowning and intentional self-harm (ICD-10 V01-99, W00-99, X00-99, Y00-36, Y85-87, and Y89) and other deaths (overall mortality minus all other previously defined cause of deaths ie, excluding mortality from ARC, other cancer, CVD, IHD and external causes).

\section{Statistical analysis}

As proposed by $\mathrm{Hu}$ et $a{ }^{17}{ }^{17}$ we applied baseline information until follow-up information became available, until of death, or emigration, whichever occurred first. Thereafter, follow-up information was applied until age of death, emigration or the end of the study period, whichever occurred first. We used Cox proportional hazard regression models to calculate HRs with $95 \%$ CIs comparing abstainers with five categories of alcohol consumption (0.1-1.49 g/day (reference group), $1.5-4.9,5-9.9,10-14.9$ and 15+ g/day). Age was used as the underlying time variable in all Cox regression analyses. The Breslow method was adopted for handling 
ties. Departures from proportional hazards assumption in the Cox models was tested through inclusion of an interaction variable between categories of alcohol intake and underlying time (age) (http://www.ats.ucla.edu/ stat/examples/asa/test_proportionality.htm).

We decided a priori to adjust for age at recruitment, smoking status (never, former, current, $\mathrm{n}_{\text {missing }}=0$ ) and duration of smoking (continuous $\mathrm{n}_{\text {missing }}=0$ ), body mass index (BMI; $\leq 18.49$, 18.5-24.9, 25-29.9, and, $\geq 30 \mathrm{~kg} / \mathrm{m}^{2}$ $\mathrm{n}_{\text {missing }}=1813$ ) and height (continuous $\mathrm{n}_{\text {missing }}=911$ ), education attainment $\left(\leq 9,10-12,13-16, \geq 17\right.$ years $n_{\text {missing- }}$ $=944$ ), physical activity score derived from self-assessment scale of 1 through 5 and considering both working and leisure time (low (1-2), middle (3) and high (4-5), total energy intake not from alcohol consumption (continuous, in $\mathrm{kJ} /$ day), number of children $\left(0,1-2, \geq 3, \mathrm{n}_{\text {missing- }}\right.$ $=0)$, age at first birth $(<20,20-24,25-29$, and $\geq 30$ years, $\mathrm{n}_{\text {missing }}=6782$ ), oral contraceptive (yes $/$ no $\mathrm{n}_{\text {missing }}=96$ ) use and duration $\left(<3,4-7, \geq 8, \mathrm{n}_{\text {missing }}=96\right)$, menopausal status and age at menopause (premenopausal, postmenopausal at $<51$ years of age, and postmenopausal at $\geq 51$ years of age $n_{\text {missing }}=1985$ ), and history of breast cancer in mother or sister (yes/no $\mathrm{n}_{\text {missing }}=0$ ).

We have used follow-up information on smoking exposure and BMI, in addition to alcohol consumption, for both complete-case analyses and analyses performed in multiple imputed data sets.

The test for trend across categories of alcohol consumption was based on the median alcohol intake (g/day) in each category. We tested for interaction between alcohol consumption and smoking status, BMI or physical activity levels. For overall mortality, we estimated the HRs of different categories of alcohol consumption in never-smokers. For overall mortality, the effect of age was further investigated by stratifying according to age at enrolment (before $(<)$ or after $(\geq$ ) 40 years of age) and age at exit (before $(<)$ or after $(\geq)$ 60 years of age). To reduce the risk of reverse causality, sensitivity analyses were run excluding women with prevalent conditions at cohort entry $(n=7316$ : cancer $\mathrm{n}=2932$, stroke $\mathrm{n}=138$, heart attack $\mathrm{n}=98$ and hypertension $\mathrm{n}=4514$, with 366 women experiencing more than one of the conditions).

In a complementary set of analyses, we started following the women for mortality from 2004 instead of 1991/ 1992. We classified them according to the change in alcohol consumption between 1991/1992 and 2004. We created seven mutually exclusive categories: stop drinking; start drinking; continue as never consumer; maintain a low level of alcohol consumption $(<5 \mathrm{~g} /$ day $)$; maintain a high level ( $\geq 5 \mathrm{~g} /$ day); increased alcohol consumption (from $<5$ to $\geq 5 \mathrm{~g} /$ day); and decreased alcohol consumption (from $\geq 5$ to $<5 \mathrm{~g} /$ day). We estimated the HRs and their 95\% CI between the 'change' variable and overall and cause-specific mortality. None of the cofactors were considered as time-varying but all models were adjusted for alcohol consumption in 1991/1992. For this analysis, models were adjusted for baseline
(1991/1992) or follow-up (2004) characteristics when we had the information (ie, smoking, physical activity and BMI).

\section{Dropping out of the study and multiple imputation}

The women who dropped out of the study at follow-up $(n=14404(29.8 \%))$ have been described elsewhere. ${ }^{12}$ Briefly, compared with women who did not drop out, the women who dropped out had lower education (35.9\% vs $27.1 \%$ ), were more often abstainers $(17.0 \%$ vs $12.2 \%$ ) and reported lower levels of daily alcohol consumption $(1.9 \mathrm{~g} /$ day vs $2.4 \mathrm{~g} /$ day $)$. In order to deal with the dropouts of the study, we used multiple imputation models,${ }^{18}$ and compared the results with complete case Cox regression analyses. Multiple imputation models were used under the assumption of data missing at random. To reduce sampling variability, we created 20 replicate data sets from the imputation simulation. ${ }^{19}$ Separate imputation models were created for overall death and cause-specific death. We used the Nelson-Aalen cumulative hazard estimator as a predictor in all the imputation models. ${ }^{20}$ We separately imputed information from women who died or emigrated before the follow-up questionnaire (age at exit < age at follow-up questionnaire: 1351 women of whom 715 died) and those who died or emigrated after follow-up (age at exit $\geq$ age at follow-up: 46898 women of whom 1385 died).

We repeated the imputation procedure after excluding women with prevalent conditions at baseline $(n=7316)$ and ran the time-varying Cox models for overall and cause-specific mortality. The estimates from 20 imputed data sets were combined using Rubin's rules in order to obtain HRs and corresponding 95\% CI. ${ }^{21}$ Finally, we compared the complete-case analysis with the results of Cox models after imputation.

All the analyses and the multiple imputations were done in SAS-V.9.4/STATA-V.13.1 (SAS Institute, USA/ Stata Corp, USA).

\section{RESULTS}

During >900 000 person/years, in 48249 women at baseline (33 845 women at follow-up), a total of 2100 deaths were recorded (table 1). The median alcohol consumption increased from $2.3 \mathrm{~g} /$ day in 1991/1992 to $4.7 \mathrm{~g} /$ day in 2004. Simultaneously, the proportion of abstainers decreased from $13.6 \%$ to $10.3 \%$ (10.8\% including women who dropped out of the study at follow-up). On average, between baseline and follow-up, the majority $(89.6 \%)$ of WLH women were drinking $<10 \mathrm{~g} /$ day (table 1 ).

Comparing point estimates (mean and percentages), abstainers had more children, were younger at the time of first birth, and were more likely to have prevalent health conditions at baseline (table 1). Women drinking more than $15 \mathrm{~g}$ /day were more often current smokers, had a longer history of smoking, were more often nulliparous, 


\begin{tabular}{|c|c|c|c|c|c|c|c|}
\hline \multirow[b]{2}{*}{ Characteristics } & \multicolumn{6}{|c|}{ Baseline (1991/92) alcohol consumption in g/day } & \multirow[b]{2}{*}{ Total } \\
\hline & $\begin{array}{l}0 \\
\text { Abstainers } \\
\mathrm{N}=6587\end{array}$ & $\begin{array}{l}0.1-1.4 \\
\text { 'Light' intake } \\
\mathrm{N}=12357\end{array}$ & $\begin{array}{l}1.5-4.9 \\
N=17272\end{array}$ & $\begin{array}{l}5.0-9.9 \\
N=8853\end{array}$ & $\begin{array}{l}10.0-14.9 \\
\mathrm{~N}=2176\end{array}$ & $\begin{array}{l}15+ \\
N=1004\end{array}$ & \\
\hline Missing at follow-up (\%) & 37.1 & 30.0 & 28.5 & 27.5 & 28.3 & 28.6 & 29.8 \\
\hline Mean (SD) age at baseline & $40.2(6.0)$ & $40.1(5.9)$ & $40.1(5.7)$ & $40.8(5.6)$ & $41.4(5.6)$ & $41.7(5.5)$ & $40.8(5.8)$ \\
\hline All death $(n)$ & 369 & 515 & 641 & 398 & 116 & 61 & 2100 \\
\hline ARC mortality $(\mathrm{n})$ & 61 & 115 & 129 & 89 & 27 & 9 & 430 \\
\hline Other cancers mortality $(n)$ & 139 & 209 & 283 & 161 & 47 & 22 & 861 \\
\hline CVD mortality $(n)$ & 41 & 40 & 50 & 35 & 6 & 5 & 177 \\
\hline IHD mortality (n) & 34 & 35 & 29 & 25 & 4 & 1 & 128 \\
\hline External causes of deaths (n) & 27 & 38 & 58 & 37 & 14 & 9 & 183 \\
\hline Other deaths $(n)$ & 70 & 87 & 100 & 56 & 22 & 17 & 352 \\
\hline \multicolumn{8}{|l|}{ Smoking status at baseline (\%) } \\
\hline Never & 51.0 & 47.6 & 41.1 & 32.5 & 26.4 & 17.6 & 41.4 \\
\hline Former & 29.7 & 33.3 & 38.8 & 43.2 & 43.4 & 44.1 & 37.3 \\
\hline Current & 19.3 & 19.2 & 20.1 & 24.3 & 30.2 & 38.3 & 21.4 \\
\hline \multicolumn{8}{|l|}{ Smoking status at follow-up (\%) } \\
\hline Never & 51.6 & 48.0 & 41.5 & 32.9 & 26.6 & 16.2 & 41.5 \\
\hline Former & 28.5 & 32.2 & 38.3 & 43.4 & 45.6 & 46.9 & 37.0 \\
\hline Current & 19.9 & 19.8 & 20.2 & 23.7 & 27.8 & 37.0 & 21.4 \\
\hline Mean (SD) smoking duration in years at baseline & 9.9 (11.9) & $10.2(11.5)$ & $11.3(11.5)$ & $13.7(11.8)$ & $16.1(12.2)$ & $19.1(11.8)$ & $11.7(11.8)$ \\
\hline \multicolumn{8}{|l|}{ Menopause status and age at menopause (\%) } \\
\hline Premenopausal & 89.6 & 91.2 & 92.0 & 91.4 & 91.0 & 90.8 & 91.3 \\
\hline Postmenopausal at $<51$ years of age & 3.5 & 3.4 & 3.1 & 3.0 & 3.4 & 3.0 & 3.2 \\
\hline Postmenopausal at $\geq 51$ years of age & 1.8 & 1.3 & 1.2 & 1.5 & 1.5 & 1.3 & 1.4 \\
\hline Unknown & 5.1 & 4.1 & 3.7 & 4.1 & 4.1 & 4.9 & 4.1 \\
\hline Mean (SD) baseline educational attainment (years) & $11.4(3.0)$ & $12.0(3.0)$ & $12.3(2.9)$ & $12.7(3.1)$ & $12.8(3.2)$ & 12.9 (3.3) & $12.2(3.0)$ \\
\hline Mean (SD) BMI $\left(\mathrm{kg} / \mathrm{m}^{2}\right)$ at baseline & $24.2(4.3)$ & 23.7 (3.9) & $24.2(4.3)$ & $23.3(3.4)$ & $23.1(3.3)$ & $23.1(3.6)$ & $23.5(3.7)$ \\
\hline Mean (SD) BMI $\left(\mathrm{kg} / \mathrm{m}^{2}\right)$ at follow-up & 26.1 (4.9) & $25.7(4.5)$ & $25.1(4.0)$ & 24.9 (3.9) & $24.9(4.1)$ & $25.2(4.2)$ & $25.3(4.3)$ \\
\hline Mean (SD) physical activity score at baseline (5 categories) & $3.0(0.9)$ & $3.1(0.9)$ & $3.2(0.9)$ & $3.2(0.9)$ & $3.2(0.9)$ & $3.0(0.9)$ & $3.0(0.9)$ \\
\hline \multicolumn{8}{|l|}{ Number of children (\%) } \\
\hline None & 15.6 & 12.4 & 12.9 & 15.2 & 19.5 & 22.1 & 14.1 \\
\hline $1-2$ & 51.51 & 58.16 & 60.93 & 60.3 & 57.86 & 54.48 & 58.55 \\
\hline $3+$ & 32.9 & 29.43 & 26.15 & 24.56 & 22.65 & 23.4 & 27.4 \\
\hline Mean (SD) age at first birth (years) & $23.6(4.5)$ & $24.2(4.4)$ & $24.3(4.4)$ & $24.5(4.6)$ & $23.4(4.6)$ & $24.3(4.8)$ & $24.2(4.6)$ \\
\hline Ever use of OC (\%) & 72.7 & 80.6 & 86.5 & 88.0 & 88.9 & 90.1 & 83.6 \\
\hline Mean (SD) duration of OC use (years) & $6.0(5.2)$ & $6.4(5.2)$ & $6.8(5.3)$ & $7.1(5.5)$ & $7.3(5.6)$ & $7.6(5.7)$ & $6.7(5.3)$ \\
\hline Mean (SD) energy except from alcoholic beverages (kJ/day) & $6315(2048)$ & $6443(1913)$ & $6427(1828)$ & $6397(1842)$ & $6396(1856)$ & $6250(1854)$ & $6405(1886)$ \\
\hline Prevalent conditions $(\%) \dagger$ & 16.2 & 14.9 & 14.8 & 14.9 & 17.1 & 16.8 & 15.2 \\
\hline
\end{tabular}

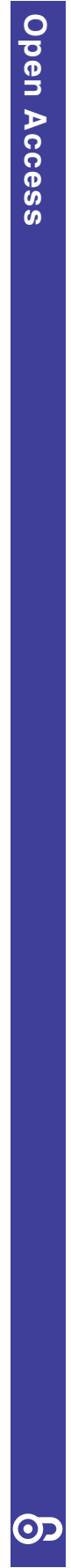


and were better educated compared with women in other alcohol consumption categories (table 1).

Abstainers at both baseline and follow-up had higher BMI and lower education and were less physically active (table 2). The proportion of those who quit both smoking and drinking (from $\geq 5 \mathrm{~g} /$ day to never) was $1.3 \%$ of those who reduced alcohol consumption.

\section{Alcohol intake (time-varying) and mortality}

Compared with light drinkers $(0.1-1.5 \mathrm{~g} /$ day $)$, a statistical null association with overall mortality was observed for all categories of alcohol consumption with the exception of never drinkers. The HR comparing never with light drinkers was 1.46 (95\% CI 1.22 to 1.74$)$ in the smoking-adjusted model, but was reduced to $\mathrm{HR}=1.22$ (95\% CI 1.02 to 1.46) in the fully adjusted model (table 3). The results were similar when women with prevalent conditions were excluded and among neversmokers only, with the exception that abstainers did not experience a statistically significantly higher risk when compared with light drinkers (data not shown).

We observed a statistically significant inverse trend between alcohol consumption and both CVD and IHD mortality ( $\mathrm{p}$ value for trend $=0.04$ and 0.02 , respectively). Compared with light drinkers $(0.1-1.5 \mathrm{~g} /$ day $)$, none of the categories of consumption reached a statistically significant level for CVD mortality. Alcohol consumption above $10 \mathrm{~g}$ /day was associated with a reduction of IHD mortality. Overall and cause-specific mortality was similar to the complete-case analysis (see online supplementary table S1). Overall mortality was similar for women enrolled in the cohort at age $<40$ and those enrolled after $\geq 40$, and also between women who exited from the cohort at age $<60$ and those who exited at $\geq 60$ years of age (see online supplementary table S2).

\section{Change in alcohol consumption and mortality}

On the basis of a reduced number of deaths, alcohol abstinence at 1991/1992 and follow-up in 2004, and those who declared that they had stopped had an increased overall mortality risk when compared with women who maintained a low $(<5 \mathrm{~g} /$ day $)$ alcohol consumption (table 4).

None of the interactions tested between alcohol intake and age smoking status, BMI and physical activity level were statistically significant in any of the outcomes investigated.

\section{DISCUSSION}

Using the WLH cohort of young and light alcohol drinking women, we observed a null association between all levels of alcohol consumption and overall and causespecific mortality while alcohol abstainers appeared at greater risk of overall mortality compared with light consumers. We observed a consistent negative association with cardiovascular and ischaemic heart disease mortality. The results were similar when women with prevalent conditions at cohort entry were excluded. Compared with maintaining a low alcohol consumption, abstinence and stop drinking between baseline (1991/1992) and follow-up (2003/2004) were associated with an increased overall mortality risk.

Study strengths included the prospective design, detailed updated assessment of alcohol consumption (reducing the within-person variation) and virtually complete long-term follow-up. We used repeated measurements of alcohol consumption, smoking and BMI in order to take into account changes in these variables over time and to attenuate the risk of measurement errors. Measurements errors such as change in the serving size may have occurred between baseline and follow-up, partly explaining the increase in alcohol consumption that we observed during this period. However, they would most likely lead to a non-differential bias and a potential underestimation of the true effect. Analyses excluding participants with morbid condition at cohort entry, and a small proportion of women who quit both smoking and alcohol drinking between baseline and follow-up suggest that reverse causality is unlikely to have driven our results. Main limitations included the small number of cases for specific causes of death, especially among women drinking $\geq 15 \mathrm{~g} /$ day. Other limitations were the self-reported alcohol consumption and that we had no information on excessive alcohol consumption in the WLH cohort. However, in Sweden, until 2004 occasional consumption of large amounts of alcohol was more often related to the behaviour of younger men, rather than middle-aged women. ${ }^{22}$ Following the International Agency for Cancer Research (IARC) and the World Cancer Research Fund (WCRF) / American Institute for Cancer Research (AICR) suggestions, ${ }^{1}{ }^{23}$ we chose not to separately study the effects of different alcohol beverages.

Compared with other similar studies, our cohort comprised younger women who drank smaller quantities of alcohol, ${ }^{4}{ }^{24}$ which has not been sufficiently described earlier. Our findings are in agreement with two recent multicentre prospective studies from the European Prospective Investigation into Cancer and Nutrition (EPIC), which found that overall mortality did not differ between light drinkers $(0.1-4.9 \mathrm{~g} /$ day or $\leq 1 \mathrm{~g} /$ day $)$ and those who consumed up to $30 \mathrm{~g} /$ day of alcohol. ${ }^{3}{ }^{4} \mathrm{We}$ found a similar increased risk of overall mortality among abstainers $(\mathrm{HR}=1.22)$ as the above-referenced EPIC studies ( $\mathrm{HR}=1.26$ and $\mathrm{HR}=1.19$, respectively). In contrast, when comparing different amounts of alcohol intake to abstinence, two meta-analyses found a J-shaped dose-response relationship between alcohol and allcause mortality. Consumption of up to 2 drinks per day (equivalent to 20-25 g/day of alcohol) was inversely associated with total mortality. ${ }^{5} 6$ The protective effect observed in some epidemiological prospective studies may be explained by the choice of the reference group. ${ }^{9}$ In order to minimise the reverse causality problem, the reference group should control for the so-called 'sick 
Table 2 Women's Lifestyle and Health cohort characteristics by change in alcohol consumption between baseline (1991) and follow-up (2004)

\begin{tabular}{|c|c|c|c|c|c|c|c|c|}
\hline \multirow[b]{2}{*}{ Characteristics } & \multirow[b]{2}{*}{$\begin{array}{l}\text { Stop } \\
2614 \\
\end{array}$} & \multirow[b]{2}{*}{$\begin{array}{l}\text { Start } \\
3924\end{array}$} & \multicolumn{6}{|c|}{ Change in alcohol consumption between baseline (1991/92) and follow-up (2004) period } \\
\hline & & & $\begin{array}{l}\text { Abstainers at } \\
\text { baseline and } \\
\text { follow-up } \\
2465\end{array}$ & $\begin{array}{l}\text { Maintain low } \\
<5 \text { g/day } \\
14941\end{array}$ & $\begin{array}{l}\text { Maintain high } \\
\geq 5 \mathrm{~g} / \mathrm{day} \\
9337\end{array}$ & $\begin{array}{l}\text { Increase } \\
11660\end{array}$ & $\begin{array}{l}\text { Decrease } \\
2165\end{array}$ & $\begin{array}{l}\text { Exit before follow-up } \\
\text { (death or emigration) } \\
1143\end{array}$ \\
\hline $\begin{array}{l}\text { Mean (SD) baseline alcohol consumption* } \\
\text { (g/day) }\end{array}$ & $1.8(3.5)$ & - & - & $1.7(1.3)$ & $9.3(5.4)$ & $2.6(1.3)$ & $7.9(6.0)$ & $4.8(6.8)$ \\
\hline Baseline abstainers (\%) & - & 60 & 37 & - & - & - & - & 3 \\
\hline $\begin{array}{l}\text { Mean (SD) follow-up alcohol consumption* } \\
\text { (g/day) }\end{array}$ & - & $4.0(10.8)$ & - & $2.4(1.5)$ & $14.3(14.2)$ & $10.2(15.4)$ & $3.3(1.2)$ & - \\
\hline Follow-up abstainers (\%) & 51.5 & & 48.5 & - & - & - & - & - \\
\hline Prevalent conditions at baseline (\%) & 5.6 & 8.4 & 5.4 & 29.3 & 19.9 & 23.1 & 4.1 & 3.9 \\
\hline Mean (SD) age at baseline (years) & $41.3(5.7)$ & $39.4(5.8)$ & $41.4(5.9)$ & $40.4(5.8)$ & $40.9(5.6)$ & $39.5(5.6)$ & $41.0(5.7)$ & $41.4(5.9)$ \\
\hline \multicolumn{9}{|l|}{ Smoking status at baseline (\%) } \\
\hline Never & 51.9 & 43.7 & 63.0 & 46.2 & 29.5 & 39.0 & 34.2 & 35.7 \\
\hline Former & 27.6 & 34.4 & 21.8 & 35.2 & 44.1 & 40.3 & 40.0 & 38.0 \\
\hline Current & 20.5 & 21.9 & 15.2 & 18.6 & 26.4 & 20.8 & 25.8 & 26.3 \\
\hline \multicolumn{9}{|l|}{ Smoking status at follow-up (\%) } \\
\hline Never & 51.0 & 42.1 & 61.8 & 45.1 & 28.6 & 37.8 & 33.4 & - \\
\hline Former & 27.7 & 33.3 & 21.5 & 34.3 & 44.1 & 40.5 & 39.0 & - \\
\hline Current & 21.3 & 24.6 & 16.7 & 20.6 & 27.3 & 21.7 & 27.6 & - \\
\hline $\begin{array}{l}\text { Mean (SD) baseline educational attainment } \\
\text { (years) }\end{array}$ & $11.5(3.1)$ & $11.4(2.9)$ & $11.3(3.2)$ & $11.9(2.9)$ & $12.8(3.1)$ & $12.4(2.8)$ & $12.4(3.0)$ & $12.4(3.7)$ \\
\hline $\begin{array}{l}\text { Mean (SD) physical activity score } \\
\text { (5 categories) }\end{array}$ & $3.0(0.9)$ & $3.0(0.9)$ & $3.9(0.9)$ & $3.1(0.9)$ & $3.2(0.9)$ & $3.2(0.9)$ & $3.1(0.9)$ & $2.9(1.6)$ \\
\hline Mean (SD) BMI $\left(\mathrm{kg} / \mathrm{m}^{2}\right)$ at baseline & $24.3(4.5)$ & $23.9(4.1)$ & $24.5(4.5)$ & $23.7(3.9)$ & $23.1(3.3)$ & $23.1(3.3)$ & $23.4(3.5)$ & $23.7(4.1)$ \\
\hline Mean (SD) BMI $\left(\mathrm{kg} / \mathrm{m}^{2}\right)$ at follow-up & $26.3(5.2)$ & $26.0(4.8)$ & $26.5(5.3)$ & $25.7(4.5)$ & $24.9(3.8)$ & $25.1(4.0)$ & $25.3(4.7)$ & - \\
\hline All death $(n)$ & 100 & 132 & 121 & 411 & 283 & 260 & 82 & 711 \\
\hline ARC mortality $(n)$ & 21 & 25 & 18 & 80 & 66 & 53 & 14 & 153 \\
\hline Other cancers mortality (n) & 39 & 47 & 52 & 184 & 119 & 122 & 36 & 262 \\
\hline CVD mortality $(n)$ & 9 & 20 & 9 & 30 & 22 & 21 & 8 & 58 \\
\hline IHD mortality (n) & 7 & 14 & 14 & 25 & 9 & 8 & 9 & 42 \\
\hline External causes of deaths $(n)$ & 3 & 3 & 6 & 19 & 17 & 17 & 7 & 111 \\
\hline Other deaths $(n)$ & 23 & 24 & 24 & 80 & 55 & 43 & 10 & 93 \\
\hline
\end{tabular}




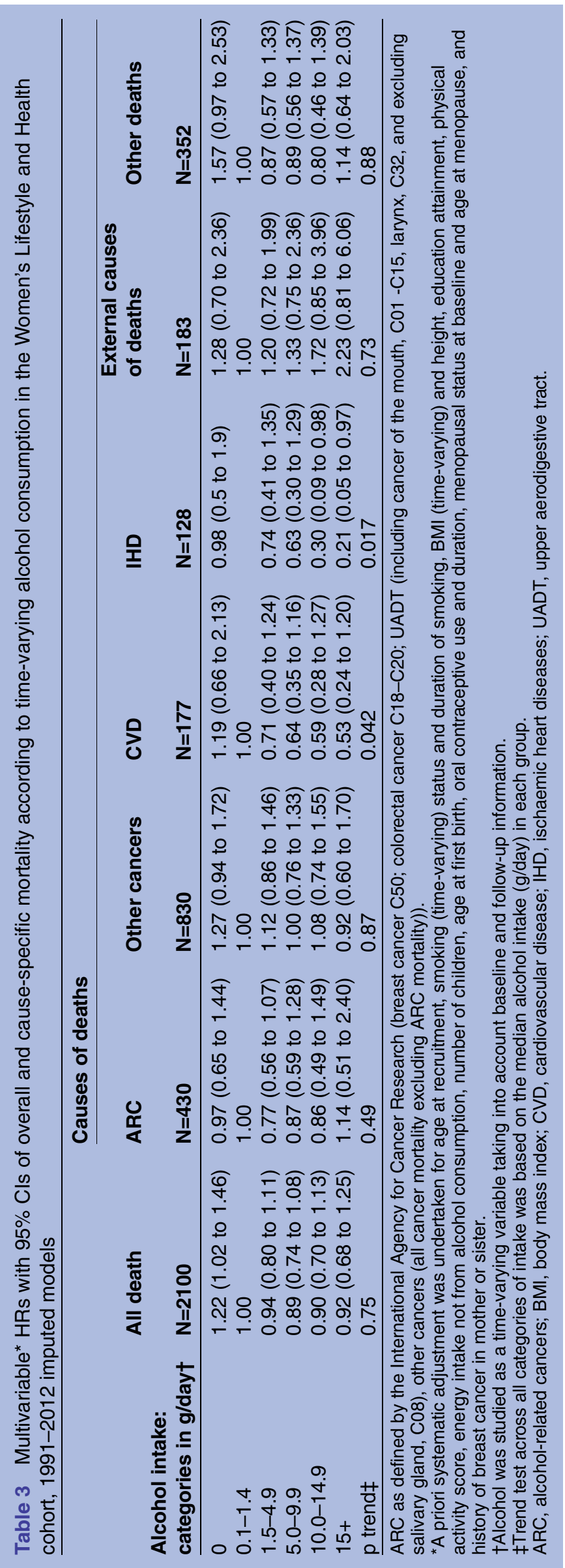

quitters', especially in European cohorts where the phenomenon of sick quitting is prevalent. ${ }^{25} 26$

We observed a higher overall mortality in abstainers and women who stop drinking. However, alcohol drinkers may differ from abstainers in unmeasured ways that influence mortality, ${ }^{27}$ and so uncontrolled confounding cannot be ruled out in our study. The risk of death of women who abstained decreased when finer socioeconomic characteristics such as income, employment status, ethnicity and social isolation were controlled for. ${ }^{28}$ We observed a decrease in abstainer's risk of overall mortality from the smoking-adjusted model to the fully adjusted model. Our results were similar when women with prevalent conditions at cohort entry were excluded; nevertheless, residual confounding for 'sick quitters' in the abstainers group could have contributed to the increased risk association for abstainers with all-cause mortality. Alcohol consumption was selfreported in our study and misclassification of the amount of alcohol intake, as well as lack of accuracy in reporting prevalent morbid conditions at baseline in the group of abstainers, could explain the excess risks observed.

For light-to-moderate alcohol consumption (up to $30 \mathrm{~g} /$ day), our results were similar to the EPIC study conducted by Ferrari et $a l^{3}{ }^{3}$ which showed no association in any of the cause-specific mortalities studied (CVD, ARC, external causes of deaths) compared with 0.1$4.9 \mathrm{~g} /$ day of alcohol intake. In contrast with this EPIC study, we did not observe a statistically increased risk in any of the cause-specific mortalities studied among abstainers. Like previous studies, ${ }^{7}$ another EPIC study, showed a lower effect on CVD mortality (excluding IHD mortality) when light-to-moderate (up to $30 \mathrm{~g} /$ day) intake was compared with light $(\leq 1 \mathrm{~g} /$ day $)$ alcohol intake. The two studies from EPIC had only one measurement of alcohol consumption and their reference group; 'light' alcohol consumption was different (0.1$4.9 \mathrm{~g} /$ day and $\leq 1 \mathrm{~g} /$ day). Cardiovascular benefits of alcohol have not been confirmed by a recent Mendelian randomisation project, ${ }^{29}$ and were limited to older women $\geq 65$ years in pooled analyses of all-cause mortality associated with alcohol consumption. ${ }^{30}$ In addition, even if low-dose alcohol consumption reduces CVD and IHD mortality, the increased incidence of cancer, ${ }^{31} 32$ traffic accidents and risk for alcohol dependence ${ }^{2}$ weaken any possible benefits. The biological explanation most often proposed for the potential 'cardioprotective' effect of alcohol is an increase in high-density lipoprotein cholesterol. ${ }^{33}$

Most cohort studies only have information on alcohol consumption at cohort entry, but alcohol consumption is likely to vary over time. ${ }^{34} 35$ In our prospective cohort study, we observed a considerable increase in alcohol consumption between 1991/1992 and 2004. In Sweden, among both men and women, over a similar period from 1990 to 2003, annual consumption based on sales increased from 7.8 to $10.3 \mathrm{~L}$ of pure alcohol per person. 


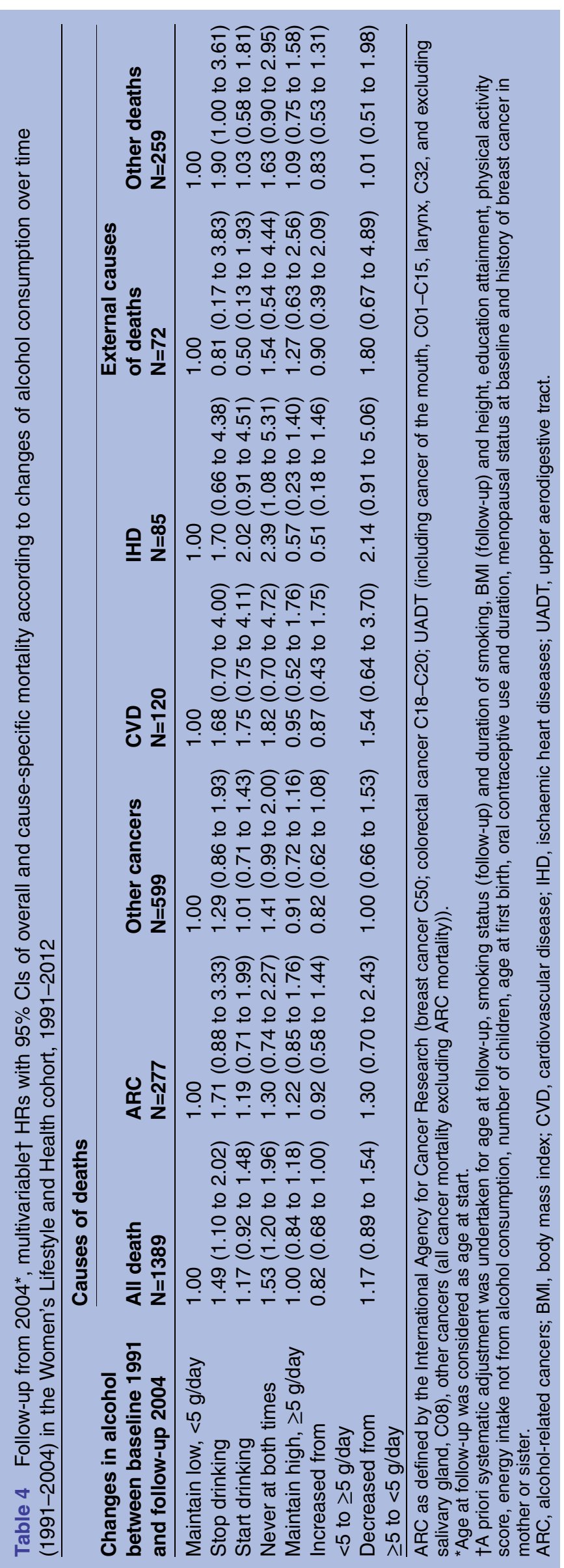

In women, few studies have investigated alcohol intake over time and mortality. ${ }^{36-39}$ Continuous abstinence over time was the reference group in three of four of the previously cited studies. In the study of Lazarus $e t a l l^{38}$ where the reference group was light-to-moderate alcohol consumption, similar to this study, none of the different groups of change over time was associated with risk of death. In the study conducted by Fillmore $e t a l,{ }^{36}$ compared with continuous abstinence, only women who maintained a former drinking status were associated with an increased risk of overall mortality with a relative risk of 1.7 (95\% CI 1.2 to 2.4). Both in men and women, starting, stopping and continuously abstaining have been associated with declining health perception in comparison to those who continued to drink. ${ }^{40}$

Under the missing-at-random assumption, we imputed missing information at baseline and follow-up. We introduced a large range of variables into the imputation models to better predict incomplete or missing data. ${ }^{41}$ However, we cannot exclude that at least some of the information is still missing-not-at-random in our data. However, results from imputed data were similar to the complete case analyses. To the best of our knowledge, this is the first study examining the effect of alcohol consumption on the risk of overall and cause-specific mortality which used repeated information on alcohol consumption and combined this method with multiple imputation.

\section{CONCLUSION}

In conclusion, in a cohort of young women, light alcohol consumption was protective for cardiovascular and ischaemic heart disease mortality but not for cancer and overall mortality.

\section{Author affiliations}

${ }^{1}$ Department of Community Medicine, Faculty of Health Sciences, UiT-The Arctic University of Norway, Tromsø, Norway

${ }^{2}$ Department of Medical Epidemiology and Biostatistics, Karolinska Institutet, Stockholm, Sweden

${ }^{3}$ Department of Epidemiology, Harvard School of Public Health, Boston, Massachusetts, USA

${ }^{4}$ Danish Cancer Society Research Center, Copenhagen, Denmark

${ }^{5}$ Department of Research, Cancer Registry of Norway, Institute of Populationbased Cancer Research, Oslo, Norway

${ }^{6}$ Genetic Epidemiology Group, Folkhälsan Research Centre, Samfundet Folkhälsan, Helsinki, Finland

Acknowledgements The authors would like to thank Marko Lukic for his help in outcome definitions and the imputation process.

Contributors IL, SS and EW conceptualised the study and defined the analytical strategy. IL and SS performed statistical analyses. IL, SS, GS, H-OA and EW provided preliminary interpretation of findings. IL, SS, GS, H-OA, NR and EW contributed by drafting the manuscript and played a key role in the acquisition of data. With respect to this work, they all critically helped in the interpretation of results, revised the manuscript and provided relevant intellectual input.

Funding This research received no specific grant from any funding agency in the public, commercial or not-for-profit sectors.

Competing interests None declared.

Patient consent Obtained. 
Ethics approval This study was approved by Institutional/Ethics Review Boards at Uppsala University and Karolinska Institutet.

Provenance and peer review Not commissioned; externally peer reviewed.

Data sharing statement Statistical code is available from the corresponding author by emailing idlir.licaj@uit.no

Open Access This is an Open Access article distributed in accordance with the Creative Commons Attribution Non Commercial (CC BY-NC 4.0) license, which permits others to distribute, remix, adapt, build upon this work noncommercially, and license their derivative works on different terms, provided the original work is properly cited and the use is non-commercial. See: http:// creativecommons.org/licenses/by-nc/4.0/

\section{REFERENCES}

1. IARC Working Group on the Evaluation of Carcinogenic Risks to Humans. Personal habits and indoor combustions. Volume $100 \mathrm{E}$. A review of human carcinogens. IARC Monogr Eval Carcinog Risks Hum 2012;100(Pt E):1-538.

2. World Health Organization. Global status report on alcohol and health 2014. 2014. WHO Library Cataloguing-in-Publication Data ISBN 9789240692763 http://www.who.int/substance abuse/ publications/global_alcohol_report/en

3. Ferrari P, Licaj I, Muller DC, et al. Lifetime alcohol use and overall and cause-specific mortality in the European Prospective Investigation into Cancer and Nutrition (EPIC) study. BMJ Open 2014;4:e005245.

4. Bergmann MM, Rehm J, Klipstein-Grobusch K, et al. The association of pattern of lifetime alcohol use and cause of death in the European Prospective Investigation into Cancer and Nutrition (EPIC) study. Int J Epidemiol 2013;42:1772-90.

5. Di Castelnuovo A, Costanzo S, Bagnardi V, et al. Alcohol dosing and total mortality in men and women: an updated meta-analysis of 34 prospective studies. Arch Intern Med 2006;166:2437-45.

6. Wang $\mathrm{C}$, Xue $\mathrm{H}$, Wang $\mathrm{Q}$, et al. Effect of drinking on all-cause mortality in women compared with men: a meta-analysis. J Womens Health (Larchmt) 2014;23:373-81.

7. Ronksley PE, Brien SE, Turner BJ, et al. Association of alcohol consumption with selected cardiovascular disease outcomes: a systematic review and meta-analysis. BMJ 2011;342:d671.

8. Stockwell T, Zhao J, Panwar S, et al. Do "moderate" drinkers have reduced mortality risk? A systematic review and meta-analysis of alcohol consumption and all-cause mortality. J Stud Alcohol Drugs 2016;77:185-98.

9. Rehm J, Gmel G, Sempos CT, et al. Alcohol-related morbidity and mortality. Alcohol Res Health 2003;27:39-51.

10. Jayasekara $\mathrm{H}$, English DR, Room R, et al. Alcohol consumption over time and risk of death: a systematic review and meta-analysis. Am J Epidemiol 2014;179:1049-59.

11. Behrens G, Leitzmann MF, Sandin S, et al. The association between alcohol consumption and mortality: the Swedish Women's Lifestyle and Health study. Eur J Epidemiol 2011;26:81-90.

12. Roswall N, Sandin S, Adami HO, et al. Cohort profile: the Swedish Women's Lifestyle and Health cohort. Int J Epidemiol Published Online First: 10 Jun 2015. doi:10.1093/ije/dyv089

13. Kumle M, Weiderpass E, Braaten $T$, et al. Risk for invasive and borderline epithelial ovarian neoplasias following use of hormonal contraceptives: the Norwegian-Swedish Women's Lifestyle and Health cohort study. Br J Cancer 2004;90:1386-91.

14. Mattsson B, Wallgren A. Completeness of the Swedish Cancer Register. Non-notified cancer cases recorded on death certificates in 1978. Acta Radiol Oncol 1984;23:305-13.

15. Ji J, Sundquist K, Sundquist J, et al. Comparability of cancer identification among Death Registry, Cancer Registry and Hospital Discharge Registry. Int J Cancer 2012;131:2085-93.

16. Baan R, Straif K, Grosse $Y$, et al. Carcinogenicity of alcoholic beverages. Lancet Oncol 2007;8:292-3.

17. Hu FB, Stampfer MJ, Rimm E, et al. Dietary fat and coronary heart disease: a comparison of approaches for adjusting for total energy intake and modeling repeated dietary measurements. $\mathrm{Am}$ J Epidemiol 1999;149:531-40.
18. White IR, Carlin JB. Bias and efficiency of multiple imputation compared with complete-case analysis for missing covariate values. Stat Med 2010;29:2920-31.

19. Sterne JA, White IR, Carlin JB, et al. Multiple imputation for missing data in epidemiological and clinical research: potential and pitfalls. BMJ 2009;338:b2393.

20. White IR, Royston P. Imputing missing covariate values for the Cox model. Stat Med 2009;28:1982-98.

21. Rubin DB. Multiple imputation after $18+$ years. J Am Stat Assoc 1996:91:473-89.

22. Centre for Social Research on Alcohol and Drugs (SoRAD). Stockholm, Sweden. 2004. Alcohol Policy Network in the Context of a Larger Europe Bridging the Gap (Btg): 2004-2006. http://btg.ias. org.uk/country-reports/sweden.html

23. World Cancer Research Fund / American Institute for Cancer Research. Food, Nutrition, Physical Activity, and the Prevention of Cancer: a Global Perspective. Washington DC: AICR, 2015.

24. Fuchs CS, Stampfer MJ, Colditz GA, et al. Alcohol consumption and mortality among women. N Engl J Med 1995;332: 1245-50.

25. Fekjaer HO. Alcohol-a universal preventive agent? A critical analysis. Addiction 2013;108:2051-7.

26. Rehm J. The role of the comparison group in epidemiology and general limitations. Addiction 2013;108:2058-9.

27. Ng Fat L, Cable N, Marmot MG, et al. Persistent long-standing illness and non-drinking over time, implications for the use of lifetime abstainers as a control group. J Epidemiol Community Health 2014;68:71-7

28. Fillmore KM, Golding JM, Graves KL, et al. Alcohol consumption and mortality. III. Studies of female populations. Addiction 1998:93:219-29.

29. Holmes MV, Dale CE, Zuccolo L, et al. Association between alcohol and cardiovascular disease: Mendelian randomisation analysis based on individual participant data. BMJ 2014;349:94164.

30. Knott CS, Coombs N, Stamatakis E, et al. All cause mortality and the case for age specific alcohol consumption guidelines: pooled analyses of up to 10 population based cohorts. BMJ 2015; 350:h384

31. Bagnardi V, Rota M, Botteri E, et al. Light alcohol drinking and cancer: a meta-analysis. Ann Oncol 2013;24:301-8.

32. Cao Y, Willett WC, Rimm EB, et al. Light to moderate intake of alcohol, drinking patterns, and risk of cancer: results from two prospective US cohort studies. BMJ 2015;351:h4238.

33. Brien SE, Ronksley PE, Turner BJ, et al. Effect of alcohol consumption on biological markers associated with risk of coronary heart disease: systematic review and meta-analysis of interventional studies. BMJ 2011;342:d636.

34. Johnstone BM, Leino EV, Ager CR, et al. Determinants of life-course variation in the frequency of alcohol consumption: meta-analysis of studies from the collaborative alcohol-related longitudinal project. J Stud Alcohol 1996;57:494-506.

35. Skog OJ, Rossow I. Flux and stability: individual fluctuations, regression towards the mean and collective changes in alcoho consumption. Addiction 2006;101:959-70.

36. Fillmore KM, Kerr WC, Bostrom A. Changes in drinking status, serious illness and mortality. J Stud Alcohol 2003;64:278-85.

37. Friesema IH, Zwietering PJ, Veenstra MY, et al. The effect of alcoho intake on cardiovascular disease and mortality disappeared after taking lifetime drinking and covariates into account. Alcohol Clin Exp Res 2008;32:645-51.

38. Lazarus NB, Kaplan GA, Cohen RD, et al. Change in alcohol consumption and risk of death from all causes and from ischaemic heart disease. BMJ 1991;303:553-6.

39. Wellmann J, Heidrich J, Berger $\mathrm{K}$, et al. Changes in alcohol intake and risk of coronary heart disease and all-cause mortality in the MONICA/KORA-Augsburg cohort 1987-97. Eur J Cardiovasc Prev Rehabil 2004:11:48-55.

40. Eigenbrodt ML, Fuchs FD, Couper DJ, et al. Changing drinking pattern does not influence health perception: a longitudinal study of the atherosclerosis risk in communities study. J Epidemiol Community Health 2006;(60):345-50.

41. White IR, Royston P, Wood AM. Multiple imputation using chained equations: issues and guidance for practice. Stat Med 2011;30:377-99. 